\title{
Electric consumption pattern from big data
}

\section{Autores}

Amelec Viloria, Hugo Hernandez-P, Omar Bonerge Pineda Lezama, Victoria Diago Orozco

\begin{abstract}
From the concept of smart grid, reaching an efficient and reliable network is a task that implies several stages and sub-stages with a defined and specific mission. In this way, the intelligent measurement stage conformed by the smart meters obtains the information of electrical consumption from the users or consumers (residential, commercial, and industrial). For this purpose, a smart metering infrastructure made of wireless telecommunications and fiber optic has been generated allows to guarantee the connectivity of the smart meters and the central office of electric companies. This paper aims to describe the use of MapReduce as a technique to obtain information about the load curve at an appropriate time to obtain trends and statistics related to the pattern of residential electricity consumption.
\end{abstract}

Palabras clave

Big data, MapReduce, Meter data management system (MDMS), Smart grid, Smart metering. 